\title{
Identifying Characters of Good Street for Greater Urban Quality of Life
}

\section{Zainuddin Ab Rahman, Sharifah Khalizah Syed Othman Thani, Rafiuddin Roslan}

\author{
Centre of Study for Landscape Architecture, \\ Faculty of Architecture, Planning and Surveying, \\ Universiti Teknologi MARA,Cawangan Selangor, Kampus Puncak Alam, \\ 42300 Bandar Puncak Alam,Selangor Darul Ehsan, Malaysia \\ dinz182@gmail.com, khalizah81@gmail.com
}

\begin{abstract}
This conceptual paper aims to demystify how the quality of streets could facilitate the street culture and shaping greater urban qualities. Numerous scholars believed that certain streets had contributed an utmost factor in shaping man's civilisation. The development of modern cities has contributed to a great loss of streets significance as spaces for socialising and dwelling in the local peoples' needs. The outcome of this paper is hoping to guide the practitioners, policy makers and urban designers to incorporate the inclusive street design towards providing a better quality of urban life.
\end{abstract}

Keywords: Urban street; Inclusive street design; City's livability; Quality of life

eISSN 2398-4279 @ 2019. The Authors. Published for AMER ABRA cE-Bs by e-International Publishing House, Ltd., UK. This is an open access article under the CC BY-NC-ND license (http://creativecommons.org/licenses/bync-nd/4.0/). Peer-review under responsibility of AMER (Association of Malaysian Environment-Behaviour Researchers), ABRA (Association of Behavioural Researchers on Asians) and CE-Bs (Centre for EnvironmentBehaviour Studies), Faculty of Architecture, Planning \& Surveying, Universiti Teknologi MARA, Malaysia. 
https://doi.org/10.21834/ajqol.v4i15.184

\subsection{Introduction}

Cities are a huge deal, they have become the residence for many and offer necessities to most world's population for ages. For that reason, city's design should be well thought to make them right. More modern cities we built to accommodate the internal and external forces, which result in the loss of city's characteristic, lack of street vitality, poor social cohesion and finally leads to the decline in urban quality of life. Hence, this paper intends to explore the characteristics and quality of urban streets that accommodate the street culture and shape the urban quality of life for its inhabitant. The related literature review will facilitate to a thorough content analysis to derive the significance and impact of urban street design on the physical, social and environmental aspect of the city's growth.

\subsection{Literature Review}

The quality of life is deliberated as a development realm and plays a significant role in users' satisfaction. According to Cubukcu and Erin (2015), specific urban setting, for example, a street could be a parameter that indicates the quality of life. This is because, a street could be one of the important element in an urban environment as it provides accessibility, interconnectivity between physical and social aspect, aesthetic, public facilities and much more. An urban environment that associated with green spaces has shown huge benefits for both of environmental and social aspects, making living quality in the urban areas improved as it promotes a healthy environment for the dwellers. As part of the important element in urban design, the role of streets determines the values of urban quality of life.

According to Lottman (1976), the Organization for Economic Cooperation and Development (OECD) has established international norms in the utilisation of social indicator for urban quality of life. OECD highlighted that fundamental social concerns could be recognised by indicating the level of health, individual development, employment and quality of working life, time and leisure, commands over goods and services, physical environment condition, personal safety and the administration of justice, social opportunity and inequality. Meanwhile, Environment Directorate for OECD has also developed set of urban and physical environment indicators that focused on quality of housing, neighbourhood, transport, access to job and urban services, weather, air, noise and vibration, density, space and condition of the land. It was intended that through this indicators, an accurate review can be established which later help to determine how people feel and understand their behaviour towards the city.

\subsection{Methodology}

The purpose of this paper is to explore the roles, characteristics and quality of streets in an urban environment to respond to local street culture and shaping greater urban qualities of life for city dwellers. This study reviewed several study and literature that has explored the past and current Quality of Life Policies of Malaysia in order to understand their relative impacts to urban streetscape. Furthermore, the implications of street's configuration and 
characteristic towards the people and its environment were explored through a conceptual review of several related literature and articles. A thorough content analysis was conducted to derive the significance and impact of urban street design on the physical, social and environmental aspect of the city's growth. The study also discussed the key elements of tangible and intangible urban street design, its configuration and unique characteristics that shall be the primary considerations when planning a city; where it could affect human experience and appreciation towards city's liveability.

\subsection{Results and Discussion}

\subsection{Street Role and Significance}

Urban street is highly related to the social and economic diversity of a city, which also greatly attributed to building good cities, improve accessibility, bringing people together, foster public life, evoke vitality, safety, comfort, participation and responsibility. Nevertheless, pedestrian often demanded to share their public right-of-way with vehicular, whereas social interaction did not occur while driving in a private car. Social life, community enjoyment and intimate engagement with the urban environment can easily happen while people walk and stroll along a lively urban street. Therefore, prioritising pedestrians needs and safety during planning stage is not an option, but a must.

Marshall Berman (1982) explains, "the essential purpose of this street, which gives it its distinctive character, is sociability: people come here to see and be seen and to communicate their vision to one another, not for the ulterior purpose, without greed or competition, but as an end in itself." Hence, a good street design promotes conducive walking environment, great public place, embrace the local spirit and offer a pleasurable driving experience for different user group as well.

Street as sociable spaces is a common connotation among urban dwellers. A sociable street should accommodate street uses and activities, giving a quality outdoor environment for life on foot. A study by Wan Ismail and Ching (2016) explores that a variety of activities, pauses and experiences are the key to lively spaces and made a place to become attractive. Sholihah and Heath (2016) also observed that when the level of activities arises, the number of social activities also increases substantially.

In general, a street has its role and function to contribute to the quality of urban life. It depends on the street attributes, its context of utilisation, types, and the location. Table 1 summarise the relationship between the goal of urban development and the street attributes that further contribute to improving the quality of life

Table 1: Summary on how the role of street could improve urban quality of life in term of environmental and social aspects

\begin{tabular}{llll}
\hline \multicolumn{2}{c}{ Goal } & \multicolumn{1}{c}{ Street attributes } & $\begin{array}{c}\text { Contribution to improve urban } \\
\text { quality of life }\end{array}$ \\
\hline $\begin{array}{l}\text { Environmental } \\
\text { sustainability }\end{array}$ & quality and & $\begin{array}{l}\text { The street that associated with these } \\
\text { features: } \\
\text { - Street greenery /urban trees etc. }\end{array}$ & $\begin{array}{l}\text { Improve air quality, water quality, } \\
\text { reduce urban heat island effect, } \\
\text { promotes outdoor thermal comfort, }\end{array}$ \\
\hline
\end{tabular}




\begin{tabular}{|c|c|c|}
\hline & $\begin{array}{l}\text { - Green infrastructure (stormwater } \\
\text { utility, thermal comfort) } \\
\text { - parkways } \\
\text { - sustainable street furniture } \\
\text { (permeable pavement, bioswales } \\
\text { or bio-retention areas) }\end{array}$ & $\begin{array}{l}\text { efficiency in energy use, promote } \\
\text { public health, environmental } \\
\text { protection and risk abatement, and } \\
\text { support green city living } \\
\text { environment. }\end{array}$ \\
\hline $\begin{array}{l}\text { Public realm, sociability and } \\
\text { economic vitality }\end{array}$ & $\begin{array}{l}\text { Street that associated with these } \\
\text { features: } \\
\text { - Street activities (plazas, street } \\
\text { corridor, boulevard, etc.) } \\
\text { - Walkable and accessible (curb } \\
\text { management, traffic calming, etc.) } \\
\text { - efficient infrastructure (i.e. } \\
\text { transportation, } \\
\text { infrastructure) } \\
\text { - provide social spaces and } \\
\text { interconnectivity (pedestrian } \\
\text { comfort) } \\
\text { - - safety elements (in term of traffic, } \\
\text { and crime prevention) }\end{array}$ & $\begin{array}{l}\text { Promote business and employment } \\
\text { opportunity, boosting local economy, } \\
\text { urban gentrification, users' } \\
\text { satisfaction, public spaces, sociable } \\
\text { streets, promote livability, public } \\
\text { surveillance and reduce street crime, } \\
\text { improve mobility, etc. }\end{array}$ \\
\hline
\end{tabular}

(Source: Adapted and modified from various authors as in reference)

\subsection{Great Street Characteristics}

\subsubsection{Accessibility}

There is no denying that the primary function of a street is to enable people to travel from one place to another and also to areas beyond it. A great street will allow public access at multiple places along the street by intersecting or crossing streets and public ways, especially for the disabled user. According to Jacobs (1993), streets with one entry for every 300 feet (90 meters) are easy to find, and some of the best streets approach that figure, but there are more entries on the busiest streets. Boulevard access streets are part of the best solution to manage private vehicular but not in the numbers of cars accommodated.

On the other hand, street accessibility will also be highly associated with parking needs, in fact, private vehicular tends to park as close as possible to their destination. Placement of parking at the back of stores or retails will result in reorientation to the rear which deadening the streets and frontages. Furthermore, large ground-level lots along street would increase the gaps in term of street definition and on-street activities, while it is not economical to introduce garages on a busy street. Although on-street auto parking is permitted in most cities, but it tends to face difficulties of keeping up with current demands.

\subsubsection{Street Definition and Boundary}

Great streets define its boundary well by demarcating its physical edges, set the street apart, keeping an eye on the street and become places to city's dwellers. Jacobs (1993) explains, "streets are defined in two ways: vertically, which has to do with the height of buildings or walls or trees; and horizontally, which has most to do with the length of and spacing between whatever is doing the defining". Good street design gets along well with its vertical elements 
(mainly buildings) where they express respect to each other, particularly in heights and the way they look. Moreover, a street should have notable starts and stops, by having physical qualities that denote its ends and help to established boundaries, identity, destinations and act as reference points.

Shape, size and regularity of the physical elements may also help to set one street apart from another, easily noticeable, legible, memorable and unique, thus improve wayfinding experience in the city. Figure 1 demonstrates that greater horizontal spacing created by building massing result in less definition on an urban street. Petaling Street, Kuala Lumpur display a decent amount of street definition and boundary through the building forms, detailing, level of street width, building heights and horizontal spacing between buildings.

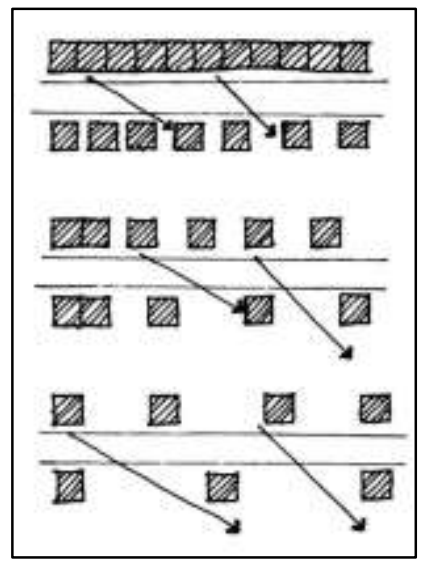

Fig. 1: Greater horizontal spacing and less street definition (Source: Jacobs, 1993)

\subsubsection{Order and Scale}

Most modern cities tend to glorify the marvels of individual freestanding building form which makes the whole city seems off-putting, messing up overall spatial qualities and deteriorating the rights of public realms. Nevertheless, an excessive order may create too many regularities and leads to visual bleak. Therefore, the ideal decision is by celebrating variety and order especially on building massing along the urban street. This can be achieved by controlling the heights, style, massing and orientation of surrounding buildings but at the same time permit some flexibility of building materials and details to the owner of the land.

Great cities should be compact and characterised by 'Fine Grain' quality in term of street width and building heights proportion. More building mass and heights would be proportioned to a wider street. Blumenfeld (1967) explain that "when the small dimensions of places exceed 450 feet (137 meters), spatial definition is weak and become more of a field than Plaza, despite the great heights of structure". Therefore, more buildings help to define urban street better than streets with fewer buildings. Hence, design for a mix of uses and destinations helps to attract mixes of people and encourage community building. 
Building and Street order is vital where it will define urban fabric and street scale. Hans Blumenfeld who heavily influence by $\mathrm{H}$. Maertens, concerned to determine "human scale" and "intimate human scale" as a reference for urban scale. "Human scale" is referred to a distance where people able to identify another people where Blumenfeld (1967) conclude that, "building height of three stories, approximate at $30 \mathrm{ft} .(9.14 \mathrm{~m})$ and width of $36 \mathrm{ft}$. $(11 \mathrm{~m})$ with a street width of $72 \mathrm{ft}$. $(22 \mathrm{~m})$, are the maximum dimensions for a building of human scale". On the contrary, "intimate human scale" referred to distances where human facial expression can be perceived, which requires building height of $21 \mathrm{ft}$. $(6.4 \mathrm{~m})$, a facade width of $24 \mathrm{ft}$. $(7.3 \mathrm{~m})$, and a street width of $48 \mathrm{ft}$. (14.6m) (Blumenfeld,1967). However, this conclusion is mainly applicable by looking buildings directly across a street, not along that street.

Ashihara (1979) observe ideal streetscape proportion by comparing distance (D) and heights $(\mathrm{H})$ ratio of the adjacent building, where spatial qualities (sense of openness) might profoundly influence the larger amount of $\mathrm{D} / \mathrm{H}$ ratio as shown in Figure 2. Meanwhile, McClauskey (1992) emphasise the degree of sense of enclosure on streetscape through width $(\mathrm{W})$ and height $(\mathrm{H})$ ratio, where enclosure become attenuated as width become greater than building heights as shown in Figure 3. McClauskey also demonstrates the impact of narrow spaces towards to higher risk of claustrophobic effects.

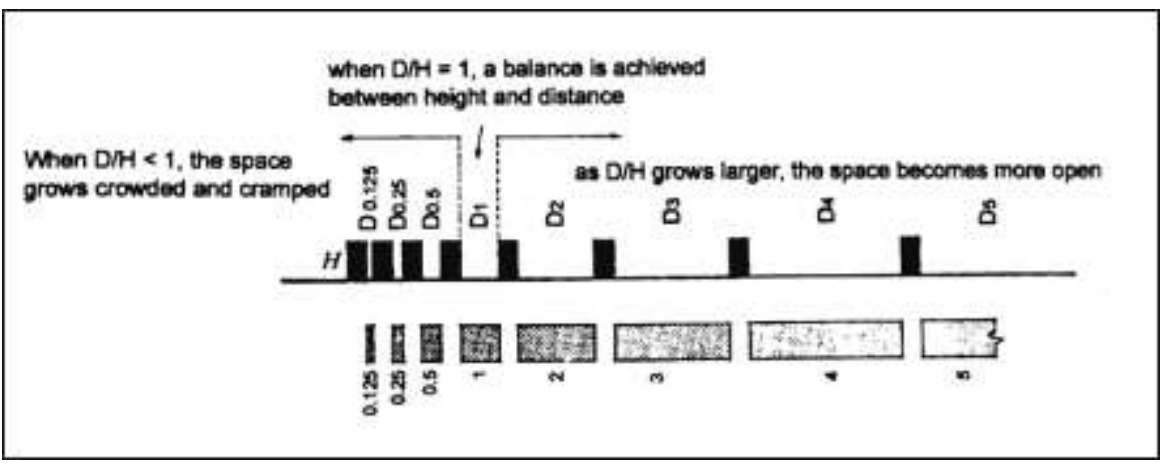

Fig. 2: Ratio of streetscape; comparison of distance (D) and height $(\mathrm{H})$ of adjacent buildings (Source: Ashihara,1979)

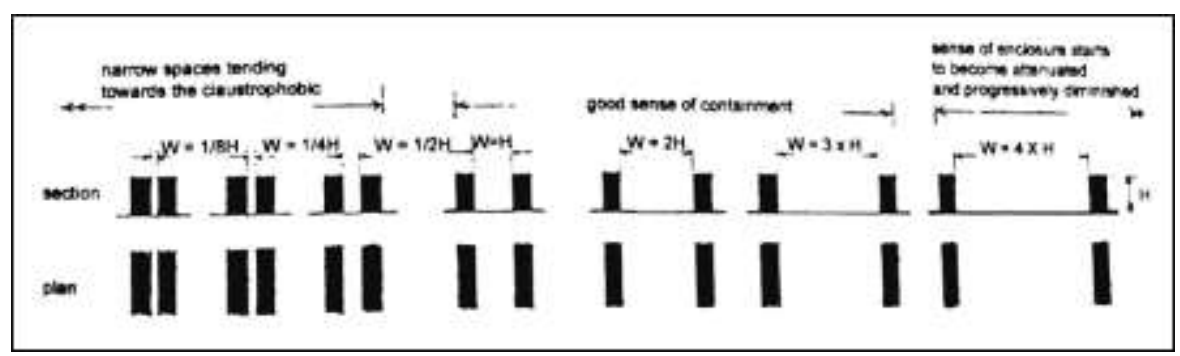

Fig.3: Comparison of width $(\mathrm{W})$ and height $(\mathrm{H})$ showing degree of enclosure of streetscape (Source: McCluskey, 1992) 


\subsubsection{Visual Engagement}

Visual complexity is the key for visual engagement, but not to the point of creating chaos and disorientation (Jacobs, 1993). Lights from street lights, signage, and store windows play important roles for visual engagements at night time as they become more legible mainly on lower level and help to navigate human sights. Shibuya Crossing in Japan, Jalan Bukit Bintang in Kuala Lumpur and Khao San Road in Bangkok are the best examples of places that celebrate life at night.

At some point, it is difficult to sustain visual interest, eye-catching and provoking features, especially on a long linear street. Moreover, if special features continue in a long distance of length, it may result in lost of its distinctiveness. Therefore, Jacobs (1993) suggest to hypothesize some points along the street with special focal point (Street Arts along Beach St, Penang), special building (Historical and Architectural value of Bangunan Sultan Abdul Samad, Kuala Lumpur), park-like spaces (the cosiness of Laman Standard Chartered, along Jalan P. Ramlee, Kuala Lumpur) or change in street section are necessary if interest is to be sustained.

\subsubsection{Visible Street Activities}

Great Streets exhibit visible life along its street corridor where the life of the city is on display. A traditional street like Jonker Street, Melaka has successfully exhibit local culture, lifestyle, expertise and craftsmanship which improve street vitality, stimulate human senses, evoke local pride and connect community with others.

Gehl (1987) argues that designs that encourage people to spend time outdoors and make interacting with other people outdoors enjoyable can make a big difference in city dwellers' quality of life. Gehl suggests that outdoor activities consist of necessary and optional activities that result in informal social interaction. Necessary activities were all activities that are more or less compulsory, while optional activities involved participation where people wish to do at possible time and place. Poor outdoor quality will result in the strict occurrence of necessary activities only, which reflect a poor character of outdoor space. People tend to engage with optional activities if the environment is pleasurable, therefore good outdoor space design result in improvement street vitality and foster optional time spent outdoor. Figure 4 shows the quality of the physical environment in relation to the presence of necessary, optional and social activities.

Appleyard and Lintell conduct a study in 1971 of three neighbouring in San Francisco and underline the dramatic impact of increased traffic in the two of the streets. Street with light traffic (2,000 vehicles per day) result in a great number of outdoor activities where kids played on the sidewalk, entrance way and steps highly occupied for outdoor stays, an immense network of neighbourhood interaction occur and residents make more friends.

On the contrary, streets with heavy traffic volume $(16,000$ vehicles per day), create a minimal presence of outdoor activities that result in poor development of neighbourhood and social interaction. On the other street, moderate traffic intensity (8,000 vehicles per day) reveal a significant reduction of outdoor activities, poor development neighbour contacts and residents make fewer friends as compared to a street with low traffic intensity. Figure 5 
demonstrate the correlation between traffic volumes and social interactions.

\begin{tabular}{|c|c|c|}
\hline & \multicolumn{2}{|c|}{ Oviality af the phrysical environment } \\
\hline & Poer & Oeod \\
\hline Necessary Retivities & & \\
\hline Optienal Aethibles & $\bullet$ & \\
\hline 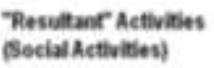 & & \\
\hline
\end{tabular}

Fig. 4: Quality of the physical environment in relation to the presence of necessary, optional and social activities

(Source: Gehl, 1987)

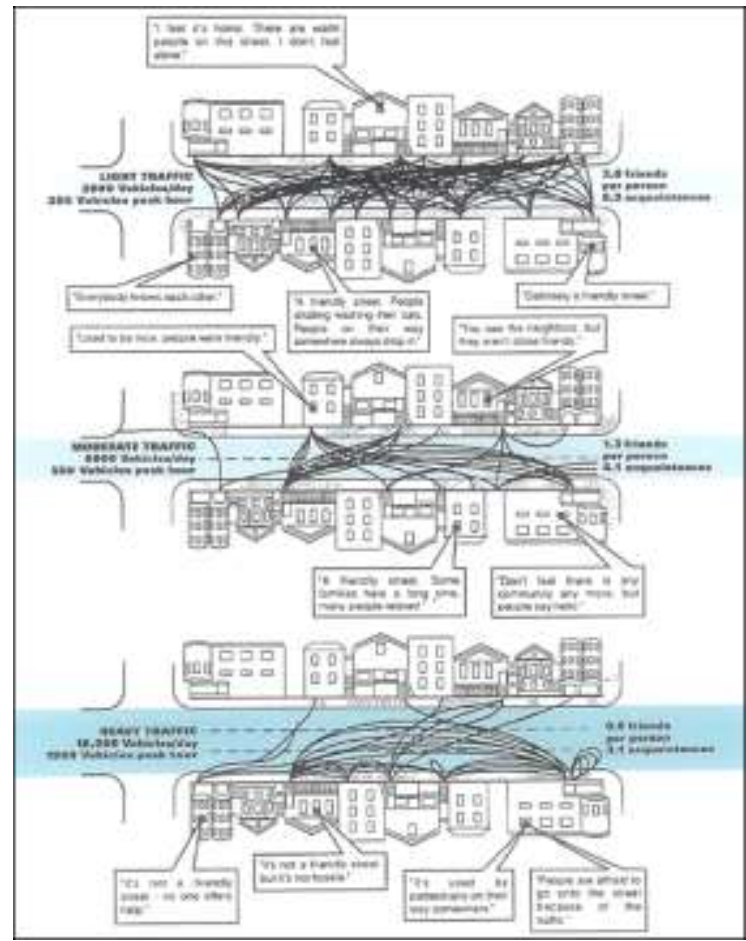

Fig. 5: The correlation between traffic volumes and social interactions. (Source: Appleyard, 1981) 


\subsubsection{Safety and Security of Streets}

Jane Jacobs observed streets and their sidewalks as vital organs to the city and become a direct representation of the people itself, thus keeping the city safe is the basic duty of streets and its sidewalks. Jacobs recommended that population size, density and heterogeneity help to create vitality, social cohesion, perception and reality of street, therefore each person must feel personally safe and secure along the street without any treats.

A great street should always be prepared to handle strangers. Therefore Jacobs suggested three main qualities of a successful street that accommodate city's neighbourhood. First, a clear demarcation between public space and private space must be drawn for the people. A good street should manage to deal with the intervention between private realms and public realms. Secondly, Jacobs emphasis on the presence of the "eyes upon the street", which belongs to the "natural proprietors" of the street. This can be achieved by adding more active building frontages along the urban street, where residents and strangers will take care and ensure the safety of both parties. This mutual partnership is also known as "social surveillance". Third, the sidewalk must have users on it fairly continuously, both to add to the number of effective eyes on the street to watch the sidewalks in sufficient numbers (Jacobs, 1961).

Apart from the above, a good street could efficiently act as a public surveillance in reducing street crime. Studies have shown that a lively and dynamic street make people more aware of their surroundings. In some cases, people keep "eyes on the street" and indirectly alert of any unusual behaviour among the users (Nor Hanisah et al., 2016; Sharifah Khalizah et al., 2016; Wan Ismail and Ching, 2016; Siti Aekbal et al., 2012). Therefore, a good street design is necessary to enhance the urban quality of life in so many aspects. It begins with the understanding of the street context where different street requires different consideration.

Moreover, sufficient quantity of stores and public places along the sidewalks are the basic requisite for social surveillance to take place. These enterprises must also be frequent and varied to provide people more choices and reason for crisscrossing path. Storekeeper and small businessmen are the best candidates to become great street watchers and sidewalk guardians as the safety of the street heavily influence their business individually. Finally, remember that people aim for food or drinks and the sights of people attract another people. Therefore the presence of these essentials keeps the presence of people on urban street and sidewalks.

\subsubsection{Minimizing Environmental Impact}

Studies have demonstrated that, by incorporating sustainable elements in street design, it has increased the outdoor quality of life; for both the physical environment and to the community (Rabiatul Adawiyah et al., 2014). It could benefit and resolves some environmental issues including thermal comfort, managing storm water runoff, reduced carbon and air pollution, giving pleasant view to the pedestrians and promotes a healthy urban environment. A study by Thani et al. (2013) observed that streetscapes with some greenery could promote outdoor thermal comfort by reducing averagely $4^{\circ} \mathrm{C}$ ambient air temperature as compared to the street without any green coverage. Street with appropriate planting elements or parkways often enhance the social values of the streets, making it better 
for both the physical and social functions.

Figure 6 shows the streetscapes associated with some greenery and its characteristics in which helps to reduce air temperature. Figure 7 shows the configuration of roadside planting that provides tree shades along the road, which helps to minimise solar infiltration and reduce surface temperature.

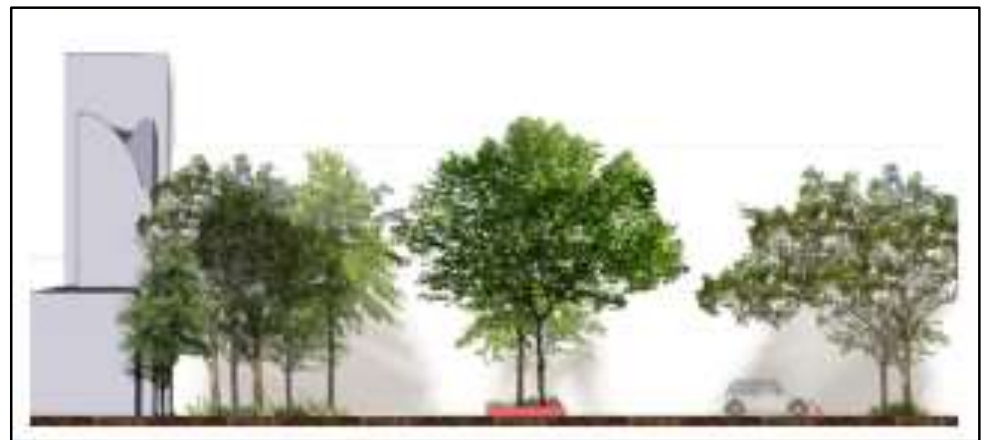

Fig.6: Street trees that could help reducing daytime air temperature

(Source: Sharifah Khalizah, 2014)

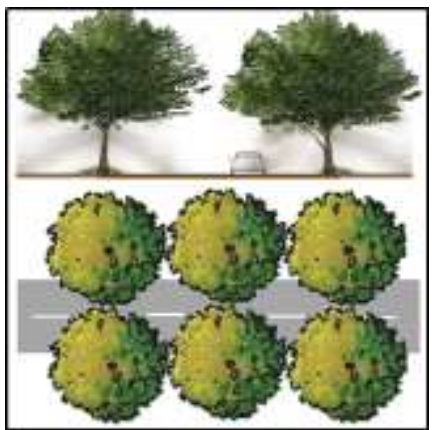

Fig. 7: Configurations of street planting that provide shades along the road.

(Source: Zulkarnaen et al.,2014)

Other than thermal comfort, the street could be designed for sustainability by imposing other types of mitigating action to overcome environmental issues. For instance, the street could be designed to manage storm water that will serve as flash flood mitigation. Enhancing the streetscape especially in flood prone area through innovative design, and by incorporating sustainable street furniture; it would not only mitigate the flash flood issues but purpose as a public realm too.

Figure 8 shows an example where the upgrading streetscape project that addresses the flood-prone area in Queens, New York has successfully worked to cater flash flood issues. The ground-breaking design features that are mimicking wave's pattern functioned well as flood protection elements to the subway station, and add the visual interest to the pedestrians 
(https://www.rogersarchitects.com/mta-flood-mitigation-street-furniture/, retrieved 17th December 2016). This modular approach has demonstrated the dynamic role of a street to manage storm water runoff, proven to act as a street-scale green infrastructure approach.

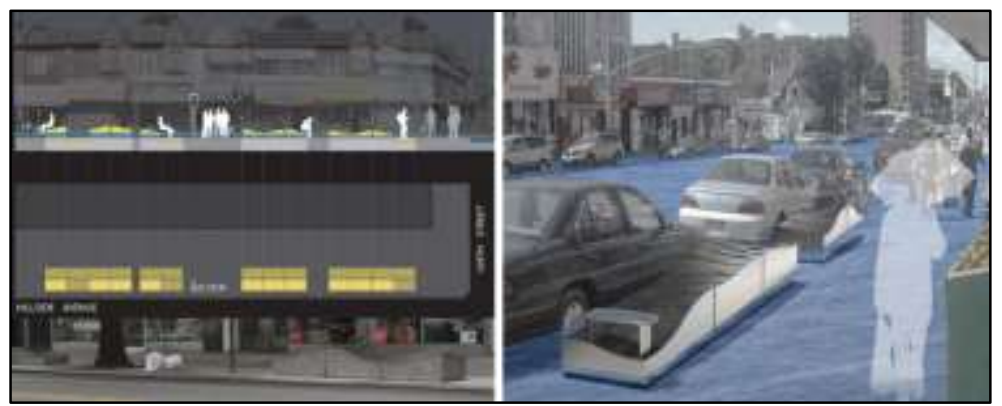

Fig. 8: An example of a streetscape project that incorporates flood mitigation design in New York. (Source: https://www.rogersarchitects.com/mta-flood-mitigation-street-furniture/, retrieved 17th December 2016).

\subsection{Conclusion}

The city needs to be robust, distinctive and has strong character, which partially is achievable through well-thought street planning and design. Since great street meant to handle strangers, a street design should able to encourage residents and strangers to create a mutual partnership in taking care of the safety and interest of both parties. Design for a mix of uses and destinations faces along urban street help to attract mixes of people and encourage community building.

Sustainable streets not only will add values to environmental and social facet but to enhance the economic vitality as well. This is because, by improving the physical condition, it indirectly transforms it into a multi-function street that potentially offers the economic opportunity where commercial and retails could be developed.

\section{Acknowledgements}

Authors would like to express gratitude to Research Management Institute (RMI), Universiti Teknologi MARA via Lestari Grant (600-RMI/DANA 5/3/LESTARI (108/2015) for providing the opportunity to make the study feasible and for the effort to cultivate research culture especially among young lecturers.

\section{References}

Anderson, Elijah. (1999) Code of The Street: Decency, Violence, and the Moral Life of the Inner City, New York: Norton.

Appleyard, Donald. (1981) Livable Streets, Berkley: University of California Press. 
Ashihara, Yoshinobu. (1979) The Aesthetic Townscape, Cambridge, Massachusetts and London: The MIT Press. Berman, Marshall. (1982) All That Is Solid Melts Into Air, New York: Viking Penguin.

Blumenfeld, Hans. (1967) The Modern Metropolis: Its Origin, Growth, Characteristics, and Planning, Paul Speiregan, ed, Cambridge: MIT Press.

Çubukçu, E., \& Erin, İ. (2015). Indicators of Quality of Life to Compare Neighbourhood Units and Regional Areas: A model to collect data in Turkish cities. Environment-Behaviour Proceeding Journal, 1(2), 205-213.

Gehl, Jan. (1987) Life Between Buildings: Using Public Space, New York: Van Nostrand Reinhold.

Jacobs, Allan B. (1993) Great Streets, Cambridge, Mass: MIT Press.

Jacobs, Jane. (1961) The Life and Death of Great American Cities, New York: Random House.

Lottman, Herbert R. (1976) How Cities Are Saved, New York: Universe Books.

McCluskey, J. (1992) Road, Form and Townscape, London: Butterworth Architecture.

MTA Flood Mitigation Street Furniture \& Urban Plan (https://www.rogersarchitects.com/mta-flood-mitigation-streetfurniture/, retrieved $17^{\text {th }}$ December 2016).

Nazri, A.F. (2008). Social Aspect of Planning: Quality Of Life.

Nor Hanisah, M. H., Sharifah Khalizah, S.O.T., Mas Ayu, J., Norkartini, M.Y. (2016). A Perceptual Study on the Influence of Vegetation Design towards Women's Safety in Public Park. Procedia-Social and Behavioral Sciences 234, 280-288.

Prime Minister's Office (2010). Tenth Malaysia Plan 2011-2015. (https://www.pmo.gov.my/dokumenattached/RMK/RMK10_Eds.pdf, retrieved 4th December 2016)

Rabiatul Adawiyah, N., Sabarinah, S.A., Azni, Z.A., Norhati, I. (2014). Adapting Human Comfort in an Urban Area: The role of tree shades towards urban regeneration. Procedia Social and Behavioural Sciences, 170, 369-380.

Sharifah Khalizah, S.O. T., Nor Hanisah, M. H., Wan Hazwatiamani, W.I. (2016). Surveillance by Design: Assessment Using Principles of Crime Prevention through Environmental Design (CPTED) in Urban Parks. Procedia-Social and Behavioral Sciences 234, 506-514.

Sharifah Khalizah, S.O.T, Nik Hanita, N.M, \& Sharifah Mastura, S.A. (2016). Influence of Urban Landscapes to Microclimatic Variances in a Tropical City. Asian Journal of Environment-Behaviour Studies, ISSN: 1394-0384, $4(16)$.

Sharifah Khalizah, S.O.T. (2014). The Influence of Urban Landscapes to the Urban Heat Island Phenomenon in Putrajaya. Unpublished Master Thesis. Universiti Teknologi MARA. Malaysia

Sholihah, A.B., Heath, T. (2016). Traditional Streetscape Adaptability: Urban gentrification and endurance of business. Environment-Behaviour Proceeding Journal, 1 (4), 132-141.

Siti Aekbal, S., Nur Suhaili, M., Zaharah, Y., Rabiatul Adawiyah, N. (2012). The Crime Ecology: Ambient Temperature vs. Spatial Setting of Crime (Burglary). Procedia Social and Behavioural Sciences, 42, 212 - 222.

Thani, S. K. S. O., N. H. N. Mohamad, and S. M. S. Abdullah. (2013). "The Influence of Urban Landscape Morphology on the Temperature Distribution of Hot-Humid Urban Centre," Procedia - Social and Behavioural Science, 85, 356- 
367.

Wan Ismail, W.H., Ching, L.H. (2016). Back Lanes as Social Spaces in Chinatown, Kuala Lumpur. EnvironmentBehaviour Proceeding Journal, 1 (3), 293-299.

Zulkarnaen, A.R., Al Junid, S.A.M., Sharifah Khalizah, S.O.T. (2014). Trees' Cooling Effect on Surrounding Air Temperature Monitoring System: Implementation and Observation. International Journal of Simulation: Systems, Science and Technology15 (2), 70-77. 